\begin{tabular}{|c|l|}
\hline Title & Synthesis of boron carbide microcrystals from saccharides and boric acid \\
\hline Author(s) & Sudoh, A kihiro; Konno, Hidetaka; Habazaki, Hiroki; Kiyono, Hajime \\
\hline Citation & $\begin{array}{l}\text { 炭素, 2007(226), 8-12 } \\
\text { https:/doi.org/10.7209/tanso.2007.8 }\end{array}$ \\
\hline Issue Date & 2007-01-15 \\
\hline Doc URL & http://hdl.handle.net/2115/72919 \\
\hline Rights & 著作権は炭素材料学会にある。利用は著作権の範囲内に限られる。 \\
\hline Type & article \\
\hline File Information & tanso226-8.pdf \\
\hline
\end{tabular}

Instructions for use 


\title{
Synthesis of boron carbide microcrystals from saccharides and boric acid
}

\author{
Akihiro Sudoh, Hidetaka Konno*, Hiroki Habazaki and Hajime Kiyono
}

\begin{abstract}
With the precursors prepared from saccharides, such as glucose and cellulose, and boric acid, microcrystals of boron carbides were synthesized at relatively low temperatures of $1500-1600^{\circ} \mathrm{C}$ by $1 \mathrm{~h}$ treatment in an argon atmosphere. Hydrothermal treatment at the stage of precursor preparation was found to be effective to form the precursors which readily decompose to boron carbides in the shape of micrometer-sized crystals. Although a small amount of free carbon is contained in the products and substituted-type boron carbides may be included, this process is interesting: precursor preparation is very simple and the raw materials are inexpensive, above all the process is not hazardous.
\end{abstract}

KEYWORDS : Boron carbide crystal, Saccharide borate ester, Glucose, Cellulose, Hydrothermal treatment

\section{Introduction}

Boron carbide is one of the hardest materials and industrially useful. Commercial processes for the production of boron carbide powder are based on the reaction between $\mathrm{B}_{2} \mathrm{O}_{3}$ and carbon ${ }^{1)}$. When carbon is used both as a reducing agent and a reactant, the process requires heat treatment at around $1700^{\circ} \mathrm{C}$ or higher. The process using magnesium metal as a reducing agent of $\mathrm{B}_{2} \mathrm{O}_{3}$ in the presence of carbon produces boron carbide at lower temperature, $1000-1200^{\circ} \mathrm{C}$, but formed $\mathrm{MgO}$ and impurities must be removed by costly post-treatment. Recently, a low temperature process in an autoclave has been reported but raw materials are toxic ${ }^{2)}$, so that it is unlikely that the process is developed on a commercial scale. We have reported that boron carbide/carbon composites are synthesized from esters of monosaccharides, such as glucose and mannose, and phenylboronic acid ${ }^{3)}$ or boric acid ${ }^{4)}$ under relatively mild conditions, e.g. $1 \mathrm{~h}$ treatment at $1400^{\circ} \mathrm{C}$ under flowing argon. In these previous works, mole fractions of boron in the stock solutions were not sufficiently large; the maximum mole ratio was $\mathrm{B}$ : onosaccharide $\left.=2: 1^{3)}, 4\right)$. Accordingly, the formed boron carbide was crystalline particles of sub-micrometers to several micrometers mixed in irregular-shaped carbon matrices. So far the reason why the microcrystals are formed from these esters is not explained, but the method can be developed to a process to synthesize boron carbide micro-crystals less contaminated with carbon by increasing mixing ratio of borate. Thus, this paper is aimed to propose a simple and relatively low cost process to produce boron carbide micro-crystals, and not to investigate detailed synthesis mechanism.

In the present work, precursors were formed with cellulose, a type of polysaccharide, as well as glucose aiming at making good use of abandoned biomass. In addition, hydrothermal treatment was applied to form precursors, expecting the promotion of ester formation which may be favorable for the conversion of precursor to boron carbides $\left.{ }^{3)}, 4\right)$.

\section{Experimental}

\subsection{Precursor preparation}

Commercially available GR grade glucose $\left(\mathrm{GL}, \mathrm{C}_{6} \mathrm{H}_{12} \mathrm{O}_{6}\right)$, cellulose $\left(\mathrm{CL},\left(\mathrm{C}_{6} \mathrm{H}_{10} \mathrm{O}_{5}\right)_{\mathrm{n}}\right)$ and boric acid $\left(\mathrm{BA}, \mathrm{H}_{3} \mathrm{BO}_{3}\right)$ were used as raw materials. The cellulose was microcrystalline powder for thin-layer chromatography, and the composition was $\mathrm{C}: 42.5, \mathrm{H}$ : 6.3, O: 51.2 mass \% or C: $27.1, \mathrm{H}: 48.3$, O: $24.6 \mathrm{~mol} \%$ by elemental analysis. Boric acid and glucose were dissolved into distilled water at a mole ratio, BA/GL, of $4 / 1$ or $5 / 1$, in which the total borate concentration was about $1.6 \mathrm{~mol} \mathrm{dm}^{-3}$. The cellulose was

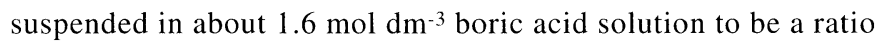
of four borate molecules per one unit of $\mathrm{C}_{6}$. Details of the preparation of precursors are summarized in Table 1 with precursor codes. One GL molecule or one unit of $\mathrm{C}_{6}$ in $\mathrm{CL}$ can form an ester with maximum two borate ions ${ }^{3)}$. Therefore, $\mathrm{GB}(2)$ of $\mathrm{BA} / \mathrm{GL}=$ 2/1 was prepared by the same method with $\mathrm{GB}(4)$ as a reference material. For GB(2) characteristic bands of borate in FT-IR spectra markedly reduced, supporting the formation of ester.

\subsection{Characterization}

The precursors were put into a graphite boat and heated to 1000 - 
Table 1 Conditions of precursor preparation and the boron content of precursor.

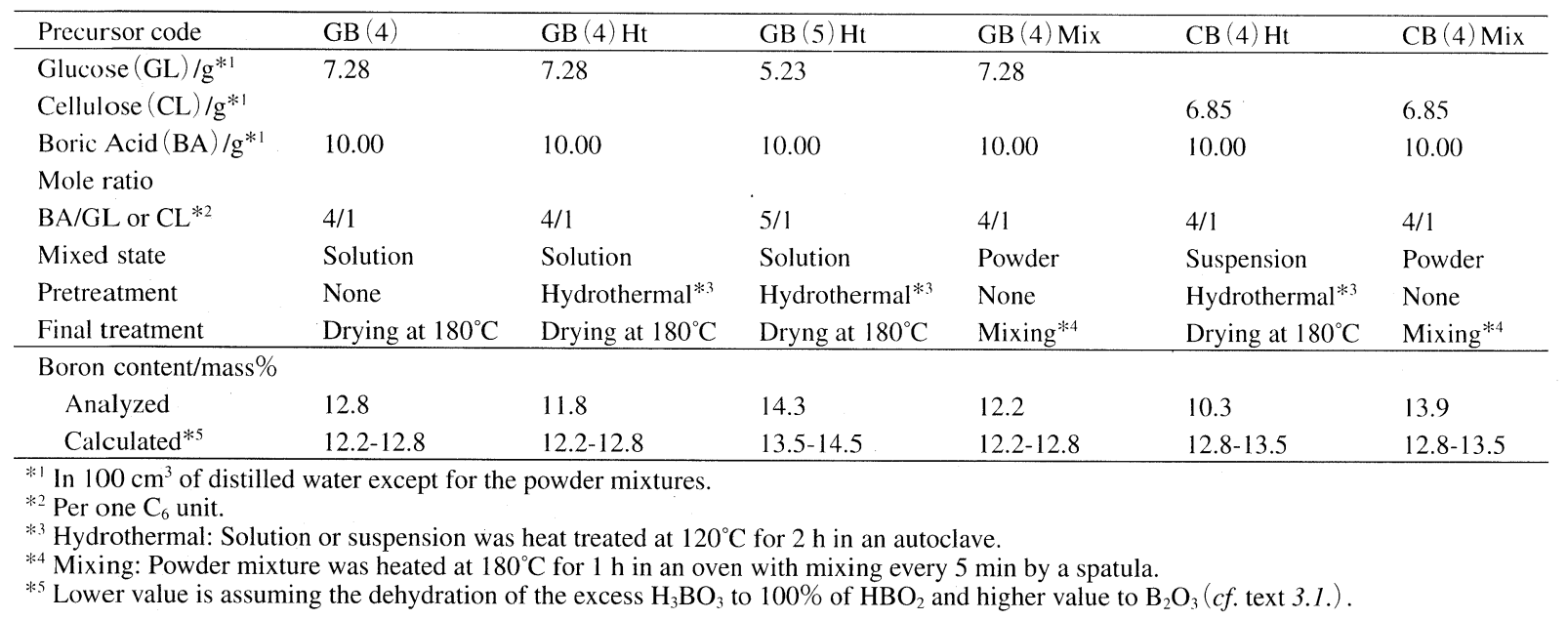

$1600^{\circ} \mathrm{C}$ at $300 \mathrm{~K} \mathrm{~h}^{-1}$ and kept for $1-10 \mathrm{~h}$ at each temperature in a flow of argon. Hereafter, the products are referred to as $\mathrm{GB}(4) \mathrm{Ht}-$ 1500 and so on, where the first symbol is the precursor code in Table 1, and the second term heat treatment temperature (HTT) in Celsius. Unless otherwise described treatment time is one hour.

The precursors and products were melted with $\mathrm{K}_{2} \mathrm{CO}_{3}$ and $\mathrm{Na}_{2} \mathrm{CO}_{3}$ at $800^{\circ} \mathrm{C}$ in a Pt crucible, cooled to ambient temperature, and dissolved in concentrated $\mathrm{HCl}$. The $\mathrm{HCl}$ solution obtained was diluted and analyzed for boron by inductively coupled plasma atomic emission spectrometry (ICP-AES, Shimadzu ICPS-IV). The precursors and products were characterized by transmission Fourier transform infrared spectroscopy (FT-IR, JASCO FT-IR-

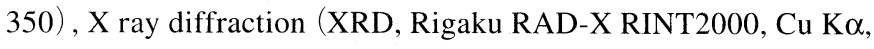
$\lambda=0.15418 \mathrm{~nm}, 2 \theta=10-90^{\circ}$ at $2 \mathrm{deg} \mathrm{min}^{-1}$ or $0.02 \mathrm{deg}$ step scan), "'B magic angle spinning nuclear magnetic resonance (MAS-NMR, Bruker MSL-300, $4 \mathrm{~T}$, pulse $4 \mu \mathrm{s}$, repetition time $4 \mathrm{~s}$, MAS $14 \mathrm{kHz}$ ), thermogravimetry (TG, SII TG/DTA32, $10 \mathrm{~K} \mathrm{~min}^{-1}$ in pure argon), scanning electron microscopy (SEM, JEOL JSM$6300 \mathrm{~F}, 2 \mathrm{kV}$ ), and transmission electron microscopy (TEM, JEOL JEM2000ES, $200 \mathrm{kV}$ ).

\section{Results and discussion}

\subsection{Characterization of precursors}

The aqueous solutions containing GL and BA became viscous by heating above $100^{\circ} \mathrm{C}$ and slurry started to precipitate with time mainly due to esterification and melting of glucose; finally light brown glass-like materials were obtained. These can be used as precursors but are not convenient to handle. Therefore, drying at $180^{\circ} \mathrm{C}$ was adopted as the final treatment to obtain powder precursors, as described in Table 1, and it was also applied to the preparation of $\mathrm{CB}(4) \mathrm{Ht}$

Glucose melts at around $150^{\circ} \mathrm{C}$ but does not decompose below $200^{\circ} \mathrm{C}$ as curve (a) in Fig.1, and dehydration of boric acid starts from around $100^{\circ} \mathrm{C}$ as curve (b). Simply mixed powder of BA/GL $=$

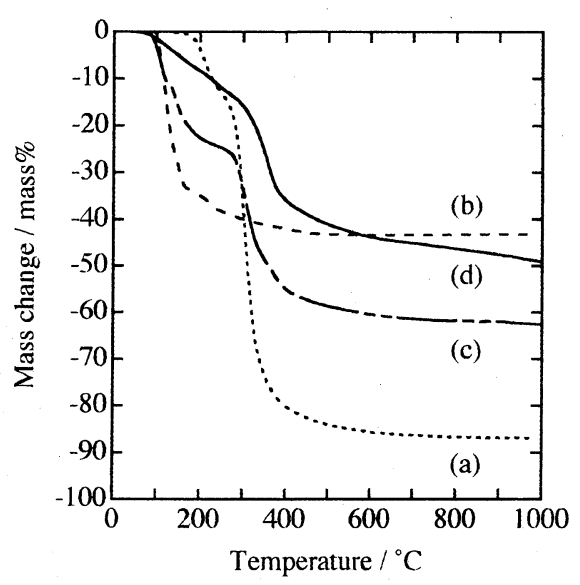

Fig.1 Thermogravimetric curves at $10 \mathrm{~K} \mathrm{~min}^{-1}$ in pure argon: (a) glucose, (b) boric acid, (c) mixed powder of BA/GL = 2/1, (d) GB(2) (cf. text 2.1.)

2/1 decomposes as curve (c), showing the superposed behavior of (a) and (b), which indicates that glucose and boric acid decompose independently. In contrast, $\mathrm{GB}(2)$ starts to decompose from around $100^{\circ} \mathrm{C}$ but the mass loss is much smaller than that of mixed powder as curve (d), showing the effect of ester formation. When esterification is completed, $\mathrm{GB}(2)$ is theoretically expressed as $\mathrm{H}_{2}\left[\left(\mathrm{C}_{6} \mathrm{H}_{8} \mathrm{O}_{10}\right)\right.$ $\left.\left\{\mathrm{B}(\mathrm{OH})_{2}\right\}_{2}\right]$, though it is uncertain that this form of compound is actually formed by the procedure in Table 1. Supposing that two $\mathrm{H}_{2} \mathrm{O}$ molecules are removed from this form by dehydration, it results in the loss of 13.5 mass \%. This value is attainted at around $275^{\circ} \mathrm{C}$ of the curve (d) in Fig.1, and a large mass loss emerges above $300^{\circ} \mathrm{C}$. Accordingly, the initial part of curve (d) suggests that the structure of $\mathrm{GB}(2)$ is similar to that described above and condensation polymerization takes place up to about $300^{\circ} \mathrm{C}$. This explains slow thermal decomposition of $\mathrm{GB}(2)$ and small mass loss at elevated temperatures. In the case of cellulose, the situation will be more complicated and cross-linking of esters may also occur by dehydration.

When there is no interaction between the esters and the excess 
amounts of boric acid added, borate may be present as metaboric acid, $\mathrm{HBO}_{2}$, and boron oxide, $\mathrm{B}_{2} \mathrm{O}_{3}$, in the precursors, since the mass loss of boric acid at $180^{\circ} \mathrm{C}$ (curve (b) in Fig.1) is 34 mass \% and larger than the loss by dehydration from $\mathrm{H}_{3} \mathrm{BO}_{3}$ to $\mathrm{HBO}_{2}$. The analyzed boron content of the precursors is shown in Table 1, where the calculated values are also shown based on the compositions of $\mathrm{C}_{6} \mathrm{H}_{14} \mathrm{O}_{10} \mathrm{~B}_{2}$ for glucose ester, $\mathrm{C}_{6} \mathrm{H}_{12} \mathrm{O}_{9} \mathrm{~B}_{2}$ for cellulose ester, and $\mathrm{HBO}_{2}$ or $\mathrm{B}_{2} \mathrm{O}_{3}$ for the excess borate. The analyzed values are the averages of a few data and most of them are close to the calculated values, though some values are slightly deviated from the calculated. If the excess borate reacted with the esters by dehydration, boron content is nearly the same with the calculated values in Table 1.

\subsection{Formation and characterization of boron carbides from glucose-based precursors}

Yield by $1 \mathrm{~h}$ heat treatment and boron content of the products from glucose-based precursors are shown in Fig.2. With all precursors, the yield steeply decreases in a HTT range between 1200 and $1400^{\circ} \mathrm{C}$ and reaches to a steady value of around 10 mass \%. In response to this, the boron content increases markedly. These drastic changes are owing to the formation of boron carbides by pyrolysis, which is confirmed by XRD as shown in Fig.3 for GB(4) Ht, for example. Diffraction peaks which resemble $\mathrm{B}_{4} \mathrm{C}$ (JCPDS 35-798) are distinguishable for $\mathrm{GB}(4) \mathrm{Ht}-1300$. In the diffraction pattern for $\mathrm{GB}(4) \mathrm{Ht}-1400$ these peaks and a small carbon 002 peak are observed but no other peaks. Above this HTT, carbon peak is not distinguishable. The results by "'B MAS-NMR were parallel to those by XRD as shown in Fig.4, in which standard spectra for reagent $\mathrm{B}_{4} \mathrm{C}\left(99 \%\right.$, Kishida Reagent Chemicals, Japan) and $\mathrm{B}_{2} \mathrm{O}_{3}$ ( $99.9 \%$, Soekawa Chemical, Japan) are also shown. For the products below $1300^{\circ} \mathrm{C}$ sharp peaks due to $\mathrm{B}_{2} \mathrm{O}_{3}$ around $0 \mathrm{ppm}$ are observed but there are no side bands which are characteristic of boron carbides. In the spectrum for $\mathrm{GB}(4) \mathrm{Ht}-1300$ sharp peaks of $\mathrm{B}_{2} \mathrm{O}_{3}$ remain but the side bands are also distinguished, indicating the formation of boron carbides. The spectrum for the products above $1300^{\circ} \mathrm{C}$ coincides with that of reagent $\mathrm{B}_{4} \mathrm{C}$, showing that the boron species

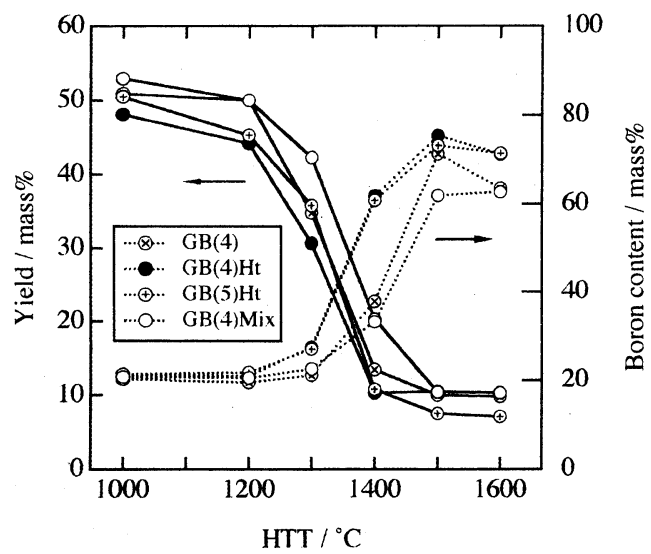

Fig.2 Yield by $1 \mathrm{~h}$ heat treatment and boron content of the products from glucose-based precursors. other than boron carbide are not predominant in these.

The results from the precursors $\mathrm{GB}(4)$ and $\mathrm{GB}(4)$ Mix compared unfavorably with those from $\mathrm{GB}(4) \mathrm{Ht}$, especially the results from $\mathrm{GB}(4) \mathrm{Mix}$ was poor. Diffraction peaks of $\mathrm{B}_{2} \mathrm{O}_{3}$ are clearly observed for GB(4) -1400 and GB(4) Mix-1400 as shown in Fig.5, while no such peaks are observable for GB(4) Ht-1400 (Fig.3). Boron content is much lower than corresponding products from GB(4) Ht (Fig.2). Boron content of these products increased by prolonged heat treatment but diffraction peaks of $\mathrm{B}_{2} \mathrm{O}_{3}$ remained even after $10 \mathrm{~h}$ treatment. In addition, carbon 002 peak remained by $1 \mathrm{~h}$ treatment at $1500^{\circ} \mathrm{C}$. Consequently, single phase of $\mathrm{B}_{4} \mathrm{C}$ (by XRD) was formed from $\mathrm{GB}(4)$ by $1 \mathrm{~h}$ treatment at $1600^{\circ} \mathrm{C}$ but not from $\mathrm{GB}(4)$ Mix. Thus, $\mathrm{GB}(4)$ and $\mathrm{GB}(4)$ Mix are less reactive than $\mathrm{GB}(4) \mathrm{Ht}$. In point of homogeneity, $\mathrm{GB}(4)$ and $\mathrm{GB}(4) \mathrm{Ht}$ are comparable because both prepared from solution and the final treatment condition was the same (Table 1). These results demonstrate

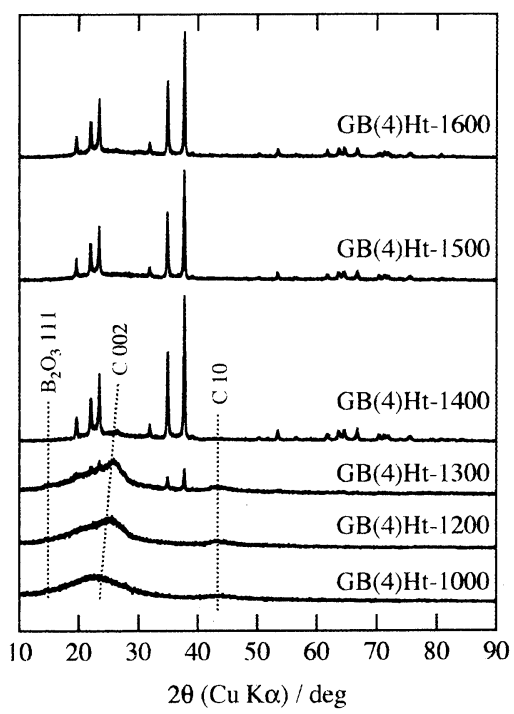

Fig.3 XRD pattern of the products from $\mathrm{GB}(4) \mathrm{Ht}$. Diffraction peaks without index are all assigned to $\mathrm{B}_{4} \mathrm{C}$ (JCPD 35-798).

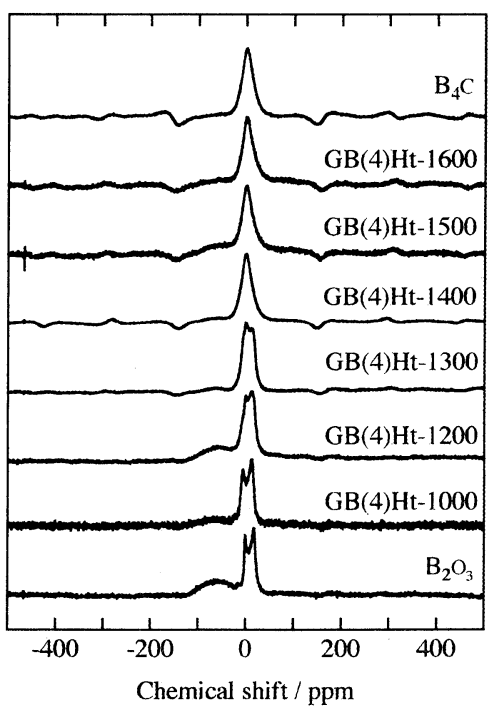

Fig.4 MAS-NMR spectra of the products from $\mathrm{GB}(4) \mathrm{Ht}$. 
effectiveness of the hydrothermal treatment for precursor preparation, suggesting that the hydrothermal treatment enhances ester formation.

As shown in Fig.2, boron content of the products at HTT $=1500$ $1600^{\circ} \mathrm{C}$ (single phase by XRD and MAS-NMR) was lower than 78.3 mass $\%$ of $\mathrm{B}_{4} \mathrm{C}$. With the intention of increasing boron content of the products, $\mathrm{GB}(5) \mathrm{Ht}$ was prepared and heat treated. Naturally, boron content in this precursor was highest (Table 1) but the content in the products was nearly the same with that from $\mathrm{GB}(4) \mathrm{Ht}(\mathbf{F i g . 2})$. Further, the yield above $1400^{\circ} \mathrm{C}$ was lowest of all (Fig.2), suggesting that evaporation of borate was prominent in this precursor. As described above, one glucose molecule can form an ester with two borate ions, so that in case of $\mathrm{GB}(5) \mathrm{Ht}$ the third excess borate may be free.

\subsection{Formation and characterization of boron carbides from cellulose-based precursors}

Fig.6 shows yield after $1 \mathrm{~h}$ heat treatment and boron content of the products from $\mathrm{CB}(4) \mathrm{Ht}$ and $\mathrm{CB}(4)$ Mix. There is no distinctive difference in the decomposition behavior of these two precursors, and the results are generally the same with that of glucose-based ones. The XRD patterns for the products, however, were clearly different as shown in Fig.7. Strong diffraction peaks of $\mathrm{B}_{2} \mathrm{O}_{3}$ are present in the pattern for $\mathrm{CB}(4) \mathrm{Mix}-1400$ and they were clearly distinguished after $10 \mathrm{~h}$ treatment, whereas they are very weak for $\mathrm{CB}(4) \mathrm{Ht}-1400$. Carbon 002 peak is broad for $\mathrm{CB}(4) \mathrm{Mix}-1400$ and sharp for $\mathrm{GB}(4) \mathrm{Ht}-1400$. These characteristic differences depending on the precursors prepared by hydrothermal method and mixing method (Table 1) are similar to the results for glucose-based precursor (Figs.3 and 5), but they are more intense for the cellulose-based precursors. This indicates that in case of $\mathrm{CB}(4) \mathrm{Mix}$, cellulose and borate independently decompose to carbonaceous materials and

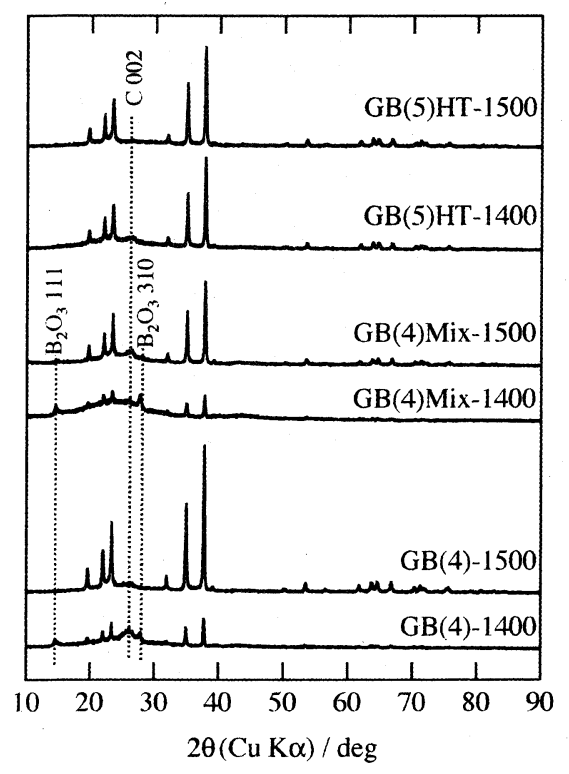

Fig.5 XRD patterns of the products from different precursors. Diffraction peaks without index are all assigned to $\mathrm{B}_{4} \mathrm{C}$ (JCPDS 35-798).
$\mathrm{B}_{2} \mathrm{O}_{3}$, and then react at higher HTT, while the formation of boron carbides from $\mathrm{CB}(4) \mathrm{Ht}$ proceeds mainly through direct pyrolysis of the integrated materials. Diffraction peaks of $\mathrm{B}_{2} \mathrm{O}_{3}$ and carbon are observed in $\mathrm{CB}(4) \mathrm{Mix}-1500$ but no such impurity peaks in the pattern of $\mathrm{CB}(4) \mathrm{Ht}-1500$. Accordingly, it is reasonably concluded that the hydrothermal treatment is effective also in the formation of cellulose-based precursor.

\subsection{Morphology and structure of boron carbide crystals}

SEM images of single phase boron carbide (by XRD) from glucosebased and cellulose-based precursors are shown in Figs.8 and $\mathbf{9}$, respectively. It is obvious that the present process produces microcrystalline boron carbide, and depending on the precursor the following features are observed:

(a) Size of crystals from $\mathrm{GB}(4) \mathrm{Ht}$ and $\mathrm{GB}(5) \mathrm{Ht}$ is about a few to $10 \mu \mathrm{m}$, and large plate-like crystals are also formed.

(b) GB (4) gives similar type crystals to those from GB (4) Ht and $\mathrm{GB}(5) \mathrm{Ht}$, but also forms agglomerated sub-micrometer

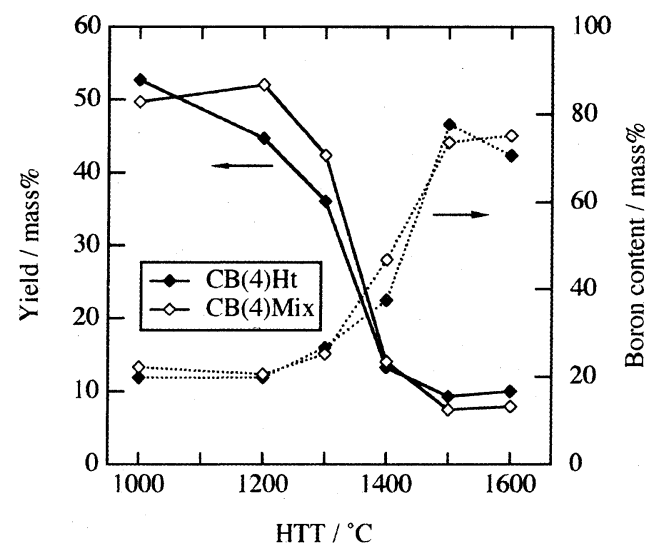

Fig.6 Yield by $1 \mathrm{~h}$ heat treatment and boron content of the products from cellulose-based precursors.

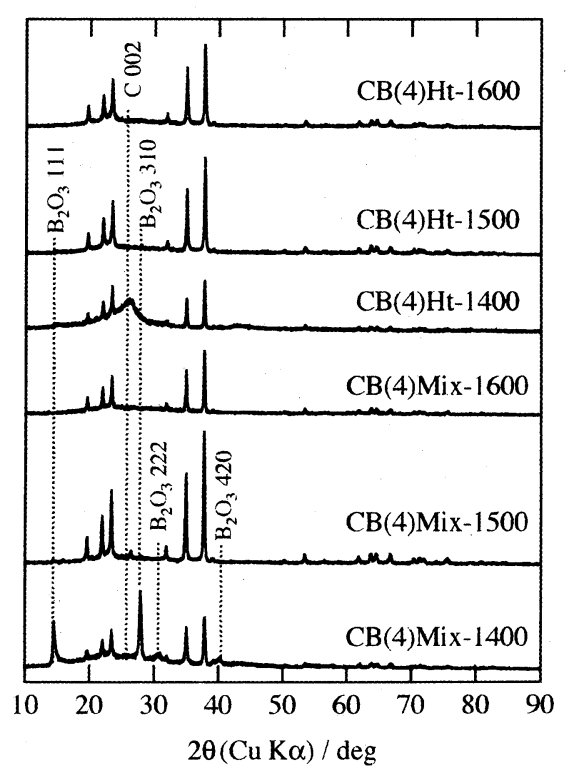

Fig.7 XRD patterns of the products from cellulose-based precursors. Diffraction peaks without index are all assigned to $\mathrm{B}_{4} \mathrm{C}$ (JCPDS 35-798). 


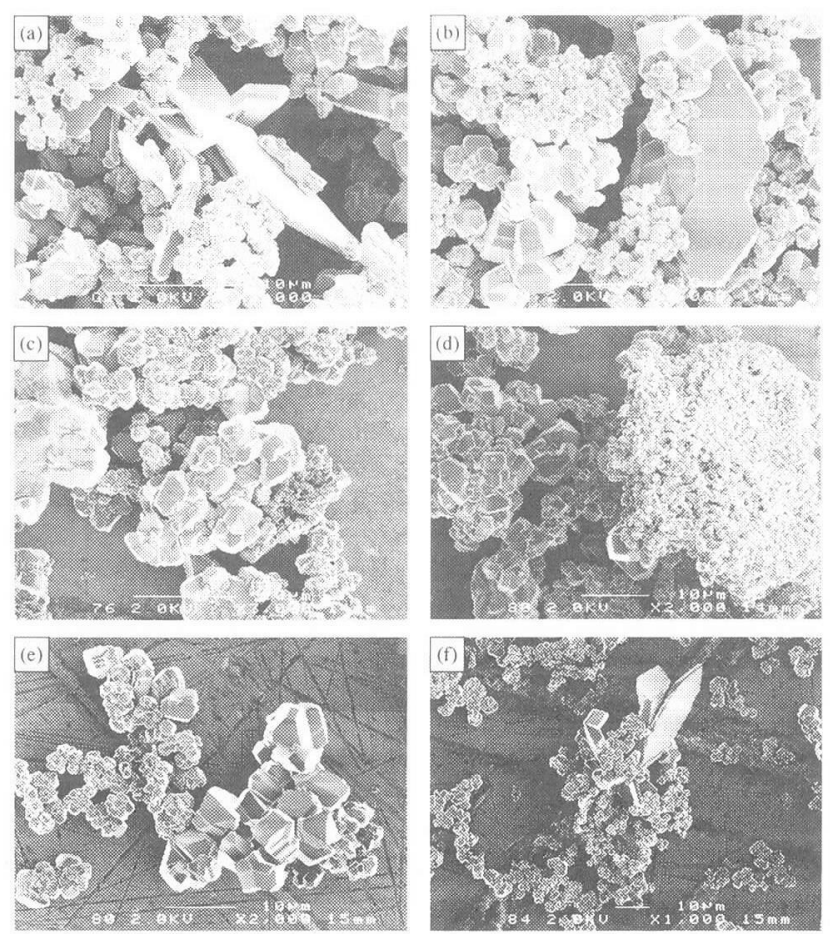

Fig.8 SEM images of the products from glucose-based precursors which were single phase by XRD: (a) GB(4) Ht-1500, (b) GB(4)Ht-1600, (c) GB(4)-1500, (d) GB(4)-1600, (e) GB(5) Ht-1500, and (f) GB(5) Ht-1600. Bars are $10 \mu \mathrm{m}$.

crystals. Plate-like crystals are not observed.

(c) Crystals from $\mathrm{CB}(4) \mathrm{Ht}$ are generally much smaller than those from the glucose-based precursors and sub-micrometer-sized particles are predominant.

By selected area electron diffraction using TEM these crystals were found to be polycrystalline, though nearly idiomorphic types were also observed by SEM. There is a tendency for larger crystals to grow from the precursors prepared from solution and by hydrothermal treatment, but detailed mechanism why such crystals are formed is not explained at present. It is only presumed that the precursors $\mathrm{GB}(4) \mathrm{Ht}$ and $\mathrm{GB}(5) \mathrm{Ht}$ melt to form a matrix having uniform composition during the heating process and crystalline particles are deposited from it during heating at constant temperature and on cooling.

The boron content of the products in Figs.8 and $\mathbf{9}$ was lower than the stoichiometric one (Figs.2 and 6), but hexagonal lattice constants were $a=0.5602 \mathrm{~nm}$ and $c=1.2083 \mathrm{~nm}$ for GB(4) Ht1500 , and $a=0.5599 \mathrm{~nm}$ and $c=1.2070 \mathrm{~nm}$ for GB(4) Ht-1600, which are close to $0.56003 \mathrm{~nm}$ and $1.2086 \mathrm{~nm}$ of $\mathrm{B}_{4} \mathrm{C}$ (JCPDS 35798). This indicates that actually boron carbide crystal is formed, though amorphous free carbon is contained. There is a wide diversity of detailed crystalline structure for boron carbide solid solution ${ }^{1)}$. The rhombohedral crystalline structure of boron carbide is commonly drawn by icosahedral $\mathrm{B}_{12}$ linked by direct covalent bonds and intericosahedral chains of $\mathrm{C}_{3}$. It is reported, however, that the central position in the $\mathrm{C}-\mathrm{C}-\mathrm{C}$ chain is partially substituted by boron atom ${ }^{5-9}$.

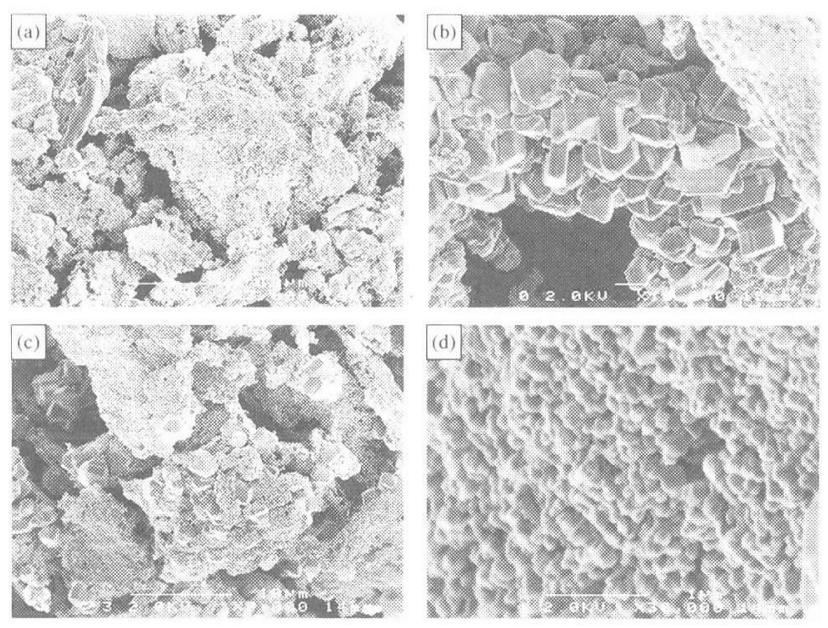

Fig.9 SEM images of the products from $\mathrm{CB}(4) \mathrm{Ht}$ which were single phase by XRD: (a) (b) $\mathrm{CB}(4) \mathrm{Ht}-1500$, and (c) (d) $\mathrm{CB}(4) \mathrm{Ht}-1600$. Bars are $10 \mu \mathrm{m}$ for (a) and (c), and $1 \mu \mathrm{m}$ for (b) and (d).

Conclusive evidence on the detailed crystalline structure was not obtained from additional measurements by FT-IR and Raman spectroscopy. Therefore, substituted-type boron carbides may be included.

\section{Summary}

Boron carbide microcrystals were synthesized from the precursors composed of glucose or cellulose and boric acid under relatively mild conditions of $1 \mathrm{~h}$ treatment at $1500-1600^{\circ} \mathrm{C}$ in an argon atmosphere. The thermal decomposition behavior of precursor, and the structure and morphology of products strongly suggest that hydrothermal treatment at the stage of precursor preparation enhances ester formation between saccharides and borate, leading to the precursors which readily decompose to boron carbides in the shape of micrometer-sized crystals. Although a small amount of free carbon is contained in the products and substituted-type boron carbides may be included, this process is interesting: precursor preparation is very simple and the raw materials are inexpensive, above all the process is not hazardous.

\section{References}

1) F. Thévenot, J. Europ. Ceram. Soc. 6 (1990) 205-225.

2) L. Shi, Y. Gu, L. Chen, Y. Quin, Z. Yang and J. Ma, Solid State Comm. 128 (2003) 5-7.

3) H. Konno, T. Erata, K. Fujita, Y. Aoki, K. Shiba and N. Inoue, Carbon 39 (2001) 779-782.

4) H. Konno, A. Sudoh, Y. Aoki and H. Habazaki, Mol. Cryst. Liq. Cryst. 386 (2002) 15-20.

5) A. H. Silver and P. J. Bray, J. Chem. Phys. 31 (1959) 247-253.

6) H. J. Becher and F. Thévenot, Z. Anorg. Allg. Chem. 410 (1974) 274-286.

7) H. Werheit, J. Less-Common Met. 117 (1986) 17-20.

8) D. R. Tallant, T. L. Aselage, A. N. Campbell and D. Emin, Phys. Rev. B 40 (1989) 5649-5656.

9) U. Kuhlmann, H. Werheit and K. Schwetz, J. Alloys and Compounds 189 (1992) 249-258 